\title{
PANORAMA ATUAL DE ATENDIMENTO À EDUCAÇÃO INFANTIL BRASILEIRA
}

\author{
Luis Henrique dos Santos Barcellos ${ }^{1}$, Julio Cesar Torres ${ }^{2}$ \\ ${ }^{1}$ Mestrando em Educação junto à Universidade Estadual Paulista (UNESP), campus de Marília. Pesquisador participante do grupo de pesquisa \\ História e Política Educacional Brasileira da UNESP. E-mail: luishbarcellos@gmail.com \\ 2 Doutor em Sociologia pelo Programa de Pós-Graduação em Sociologia da Universidade Estadual Paulista - UNESP, Araraquara. Professor do \\ Departamento de Educação da UNESP/São José do Rio Preto, e do Programa de Pós-Graduação em Educação da UNESP/Marília, SP.
}

\section{RESUMO}

O presente trabalho discute a temática da Educação Infantil, primeira etapa da Educação Básica (LDBEN 1996), analisando o panorama atual de atendimento a esse nível de ensino. Com base nos dados atuais do censo escolar, foi traçado um perfil dos estudantes. Utilizou-se como procedimento metodológico a pesquisa bibliográfica e documental. Os dados da pesquisa foram retirados dos seguintes documentos: Anuário Brasileiro da Educação Básica 2013 e do Plano Nacional de Educação - PNE 2014-2024. Os resultados desta pesquisa permitem a conclusão de que existe um perfil predominante das crianças que frequentam a Educação Infantil brasileira, em sua maioria: crianças brancas, moradoras de região urbana e economicamente favorecidas, com maior frequência à pré-escola em detrimento do segmento creche.

Palavras-chave: políticas educacionais; Educação Infantil; políticas de educação infantil; perfil dos estudantes.

\section{CURRENT PANORAMA OF ATTENDANCE TO BRAZILIAN CHILDREN EDUCATION}

\begin{abstract}
This investigation discusses the theme of early childhood education which is considered as the first stage of basic education in Brazil (LDBEN 1996), when the current panorama of attendance at this educational level has been investigated. Based on this scenario, a profile of the students of this stage of basic education was defined. The methodology adopted is that of bibliographical and documentary research. The data for this research were taken from the following documents: Anuário Brasileiro da Educação Básica (2013) and Plano Nacional de Educação - PNE 2014-2024.. The results of this research show that there is a predominant profile of children been attended at brazilian child education, when it can be noted in the majority of them: white children, children who live in urban areas and those from economically favored families, so we have more children taking place in preschool than in daycare institutions.
\end{abstract}

Keywords: Educational Policies; Early Childhood Education; Child Education Policies; Profile of Students.

\section{INTRODUÇÃO}

O presente trabalho discute a temática da Educação Infantil, primeira etapa da Educação Básica (LDBEN 1996), quando foi analisado o panorama atual de atendimento nesse nível de ensino. Com base nesse panorama, foi possível definir um perfil dos estudantes desta etapa da Educação Básica. A metodologia adotada foi a pesquisa de natureza bibliográfica e documental, que consiste no levantamento e na análise da produção de pesquisadores sobre o tema, bem como a legislação concernente à Educação Infantil. Nesse sentido, os dados para essa pesquisa foram retirados dos documentos: Anuário Brasileiro da Educação Básica 2013 (CRUZ; MONTEIRO, 2013) e do Plano Nacional de Educação PNE 2014-2024: Linha de Base (BRASIL, 2015). Os dados apresentados no decorrer do trabalho demonstram desigualdades no atendimento por seguimento (creche e préescola), revelando enormes disparidades entre eles; além disso, observa-se uma grande participação do setor privado na oferta da Educação Infantil, além de desigualdades regionais e outras diferenças no atendimento, 
como ao se considerar as áreas rural e urbana; questões ético-raciais, e sobre o fator renda.

Antes de adentrarmos o objeto de investigação, destacamos alguns marcos históricos importantes para pensarmos 0 presente trabalho com a investigação a respeito do panorama atual de atendimento à Educação Infantil.

A Educação Infantil, em especial o segmento creche (crianças de 0 a 3 anos), seja domiciliar, empresarial, particular ou pública, tem suas raízes no assistencialismo (tradicionalmente vinculadas às secretarias ou pastas de assistência social), ou seja, dedicavam-se ao cuidado e provimento das necessidades das crianças, sem uma preocupação pedagógica explícita.

Na quarta última parte dos anos 1900, a educação infantil brasileira vive intensas transformações. É durante o regime militar, que tantos prejuízos trouxeram para a sociedade e para a educação brasileira, que se inicia esta nova fase, que terá seus marcos de consolidação nas definições da Constituição de 1988 e na tardia Lei de Diretrizes e Bases da Educação Nacional, de 1996. A legislação nacional passa a reconhecer que as creches e pré-escolas, para crianças de 0 a 6 anos, são parte do sistema educacional, primeira etapa da educação básica. (KUHLMANN JR., 2000, p.6)

É com a Constituição Federal de 1988 que se começa a trilhar um novo caminho para a Educação Infantil, pois o texto legal define a oferta de creche e pré-escola no campo educacional, ou seja, a desvinculação da educação infantil, com as secretarias de assistência social, e a efetiva alocação desse nível de atenção à criança no plano da educação. Ainda prescreve como dever do Estado assegurar o atendimento às crianças pequenas, e a Educação Infantil passa a ser direito da criança. Segundo o artigo 208, inciso IV, "o dever do Estado com a educação será efetivado mediante a garantia de: [...] IV - atendimento em creche e pré-escola às crianças de zero a seis anos de idade." (BRASIL, 1988)

Outro ponto de suma importância previsto na legislação é referente à nomenclatura das instituições de educação infantil. Definindo em seu artigo 30 que "a educação infantil será oferecida em: I - creches, ou entidades equivalentes, para crianças de até três anos de idade, II - pré-escolas para as crianças de quatro a seis anos de idade." (BRASIL, 1996)

Portanto, as designações de instituições de educação infantil agora são regulamentadas por lei. Desse modo, a educação para as crianças pequenas deverá acontecer em creches, para atendimento de crianças de um dia a três anos e onze meses, e pré-escolas para crianças de quatro a cinco anos. Essa definição, apesar de importante por sua função normatizadora, não impede que existam diferenças entre creche e pré-escola.

Considerando esses marcos históricos, a implementação das políticas educacionais atuais em relação à Educação Infantil, e os dados disponíveis nos documentos que foram tomados como base para esta pesquisa, buscamos traçar o perfil dos estudantes desta etapa da Educação Básica.

\section{METODOLOGIA}

A metodologia adotada nesta investigação é a de pesquisa bibliográfica e documental, que consiste no levantamento e na análise da produção de pesquisadores sobre o tema, bem como a documentos e à legislação concernente à Educação Infantil.

A pesquisa bibliográfica funciona como aporte teórico, que irá fundamentar o objeto de estudo. Nesse sentido, foram levantadas e analisadas produções de pesquisadores da área da história da educação, e estudos sobre políticas da educação infantil.

A pesquisa documental se aproxima da pesquisa bibliográfica. $O$ que as diferencia é a natureza das fontes, pois enquanto na pesquisa bibliográfica nos valemos de fontes secundárias que remetem às contribuições de diferentes autores sobre a temática, as fontes documentais são primárias, ou seja, não receberam tratamento analítico. Nesse sentido, "na pesquisa documental, o trabalho do pesquisador requer uma análise mais cuidadosa, visto que os documentos não passaram antes por nenhum tratamento científico". (OLIVEIRA, 2007, p. 70) 
Ainda sobre a pesquisa documental, ressaltamos que a mesma torna-se um importante suporte histórico. Os documentos são importantes fontes de informação, pois permitem apreciar e valorizar a riqueza das mesmas, embora saibamos que essa fonte de dados pode ser sim manipulável, mas ainda representa uma fonte rica, confiável e estável.

[...] o documento escrito constitui uma fonte extremamente preciosa para todo pesquisador nas ciências sociais. Ele é, evidentemente,

insubstituível em qualquer reconstituição referente a um passado relativamente distante, pois não é raro que ele represente a quase totalidade dos vestígios da atividade humana em determinadas épocas. Além disso, muito frequentemente, ele permanece como o único testemunho de atividades particulares ocorridas num passado recente.

(CELLARD, 2008, p. 295)

Portanto, para se alcançarem os objetivos propostos, procedeu-se à busca e análise da legislação, resoluções normativas, diretrizes e documentos oficiais pertinentes à área educacional, em especial no tocante à educação infantil.

Por meio de dados retirados dos documentos Anuário Brasileiro da Educação Básica 2013 (CRUZ; MONTEIRO, 2013) e do Plano Nacional de Educação PNE 2014-2014: Linha de Base (BRASIL, 2015), realizamos uma análise buscando apreender como está o atual cenário em relação ao atendimento na Educação Infantil.

\section{RESULTADOS}

Os dois primeiros gráficos a seguir indicam a evolução da porcentagem de crianças do segmento pré-escola, com faixa etária de 4-5 anos (gráfico 1), e do segmento creche, faixa etária de 1 dia a 3 anos (gráfico 2) que frequentavam a Educação Infantil no Brasil, no período de 1995 a 2011.

Gráfico 1. Evolução da frequência a pré-escola no Brasil (1995-2011)

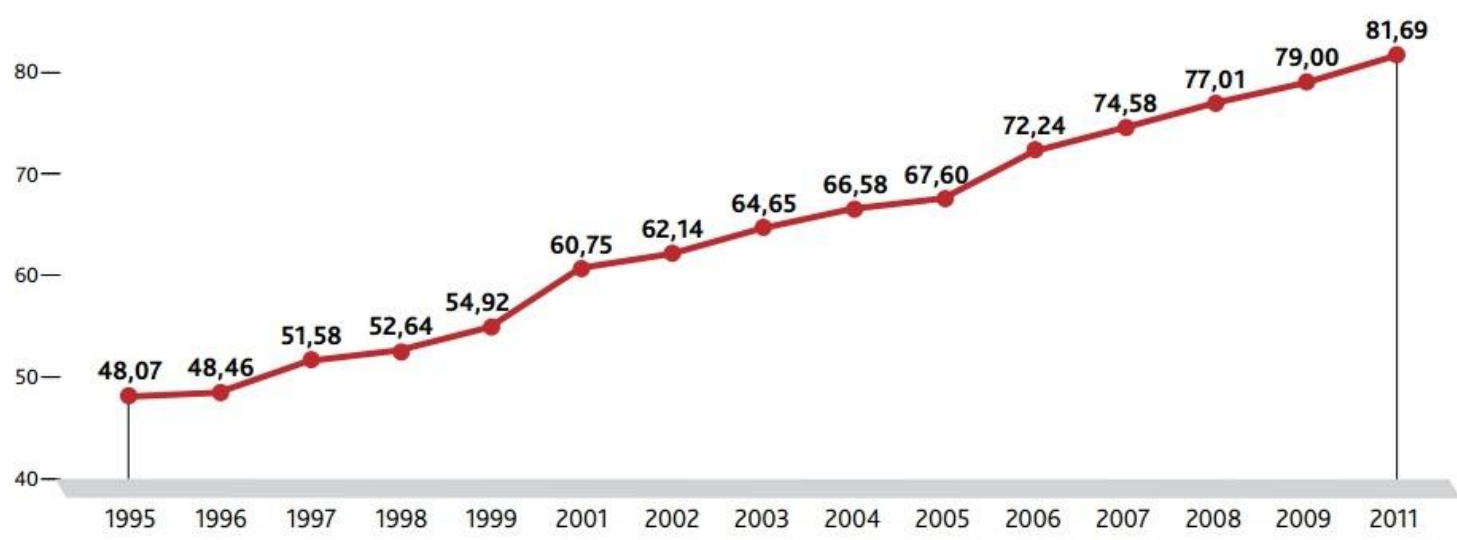

Fonte: Cruz, Priscila; Monteiro, Luciano (2013, p.15)

Observando-se o gráfico 1 , podemos notar um crescimento constante e significativo no atendimento à faixa etária de 4 a 5 anos, ao longo dos anos, atingindo em 2011 o expressivo número de $81,69 \%$ de atendimento na préescola, sendo que a porcentagem que estava fora da escola desse nível educacional é de 18,31\%.
Porém, uma leitura mais atenta, para além de dados quantitativos, revela que esse percentual esconde desigualdades que são observadas, principalmente por diferenças regionais e econômicas no tocante ao atendimento das crianças, do qual trataremos mais adiante. 
Gráfico 2. Evolução da frequência à creche no Brasil (1995-2011)

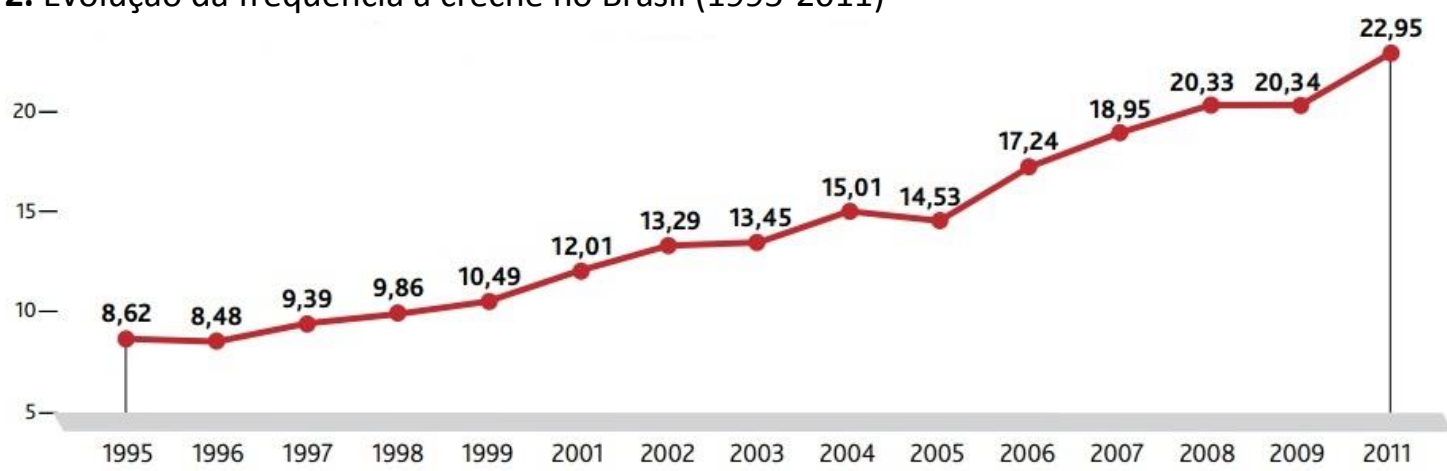

Fonte: Cruz, Priscila; Monteiro, Luciano (2013, p.14)

No gráfico 2, notamos que embora em alguns anos a taxa de atendimento para a faixa etária de 0 a 3 anos caia, a mesma volta a subir no ano subsequente. Mesmo que o crescimento da taxa de frequência tenha subido, ainda é irrisória para um país que se diz preocupado com a educação das crianças pequenas.

Diferentemente da situação apresentada no gráfico 1, a creche está longe de ser universalizada, pois, a comparação entre os gráficos revela as diferenças gritantes de atendimento entre creche e pré-escola que, em
2011, atendiam, respectivamente, a 22,95\% e $81,69 \%$ da população em idade escolar, revelando, portanto, o baixo atendimento em nível de creche.

Verificamos o mesmo no gráfico 3, que demonstra as matrículas na Educação Infantil em 2011, em números absolutos. Esse gráfico revela, portanto, como já afirmamos anteriormente, que a prioridade no que se refere à Educação Infantil está dada ao segmento pré-escola.

Gráfico 3. Matrículas na Educação Infantil por segmento de ensino (2011)

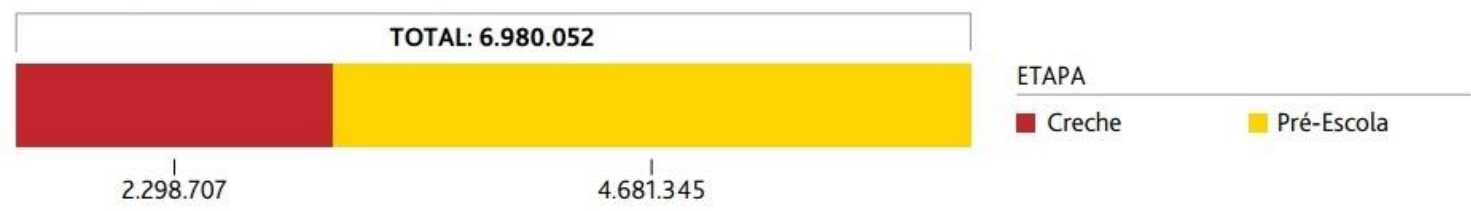

Fonte: Cruz, Priscila; Monteiro, Luciano (2013, p. 16)

Já o quarto gráfico demonstra as matrículas por dependência administrativa, revelando, como era de se esperar, que a grande parte das matrículas está no âmbito municipal, apenas uma pequena parte na esfera estadual, e somente 2.552 matrículas em âmbito federal. Também chama atenção o grande número de matrículas na rede privada que representavam, em 2011, aproximadamente $28,06 \%$ do total.

Gráfico 4. Matrículas na Educação Infantil por dependência administrativa (2011)

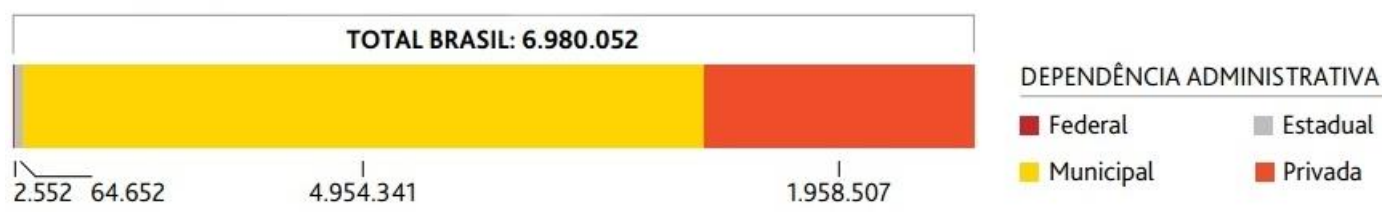

Fonte: Cruz, Priscila; Monteiro, Luciano (2013, p.16).

Como já destacamos, ao analisarmos algumas especificidades quando observamos os números absolutos, podemos notar importantes desigualdades, em especial regionais e econômicas. 
Gráfico 5. Percentual da população brasileira de 4-5 anos que frequenta a escola, por grandes regiões.

2004

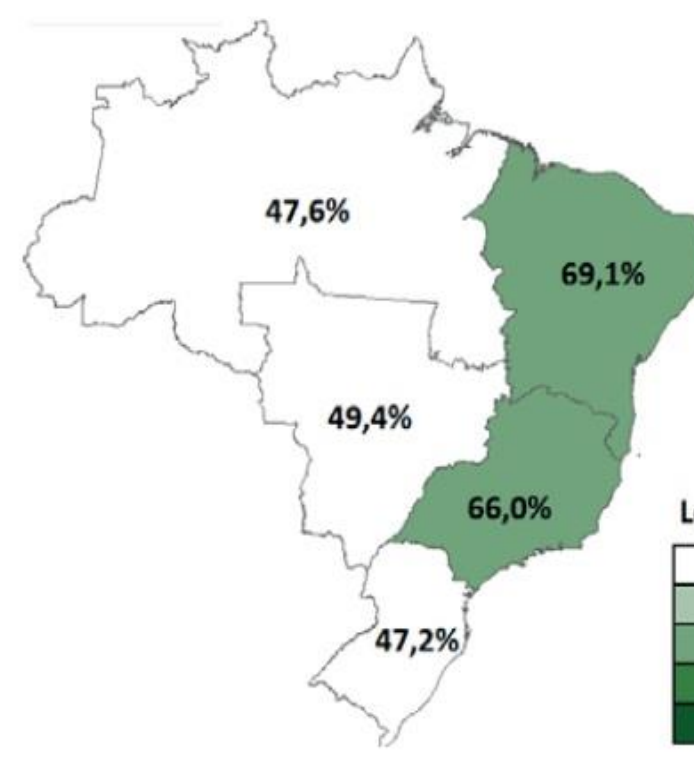

2013

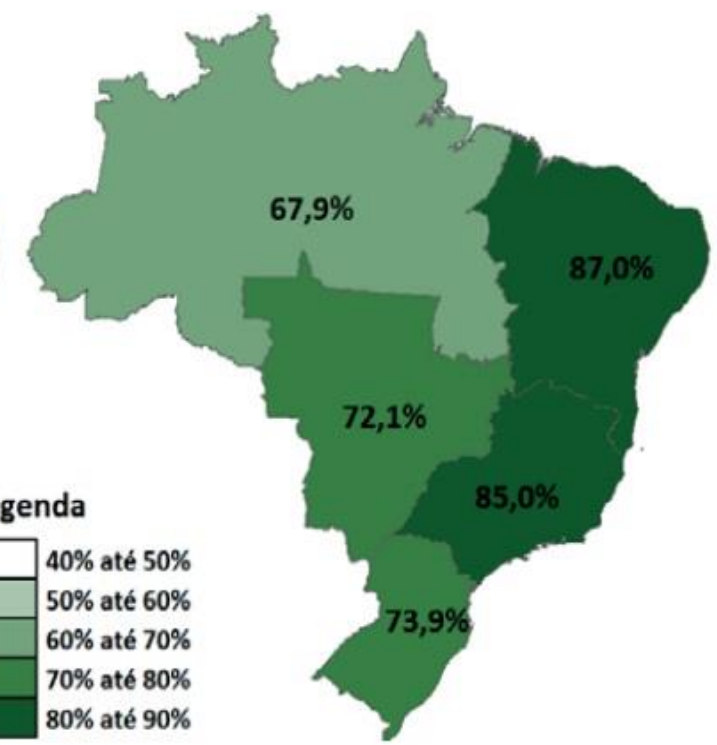

Fonte: Brasil, (2015, p. 24)

Quando analisamos a frequência à préescola por grandes regiões, notamos que embora a porcentagem de frequência tenha aumentado em todas as regiões brasileiras (gráfico 5), somente as regiões Nordeste $(87,0 \%)$ e Sudeste $(85,0 \%)$ têm o atendimento à população de $4-5$ anos praticamente universalizado em 2013. A maior diferença no crescimento percentual entre os anos de 2004 e 2013 está para as regiões Sul $(26,7 \%)$, e Nordeste $(17,9 \%)$ com o menor crescimento. Interessante notar que a região Sul em 2004 tinha o menor percentual de frequência, e foi a que mais cresceu, chegando à marca de 73,9\% em 2013. Já a frequência à creche em 2004 na região Nordeste representava $69,1 \%$, sendo o menor crescimento percentual, de apenas $17,9 \%$ no período, chegando, mesmo assim, ao maior número de frequência nacional em 2013 (87\%). A região Norte parte, em 2004, de um dos menores percentuais de frequência $(47,6 \%)$, perdendo apenas para o Sul e, em 2013, passa a ser a região com a menor frequência (apenas 67,9\%), tendo um crescimento de apenas $20,3 \%$.

Gráfico 6. Percentual da população brasileira de 0-3 anos que frequenta escola, por grandes regiões.

2004

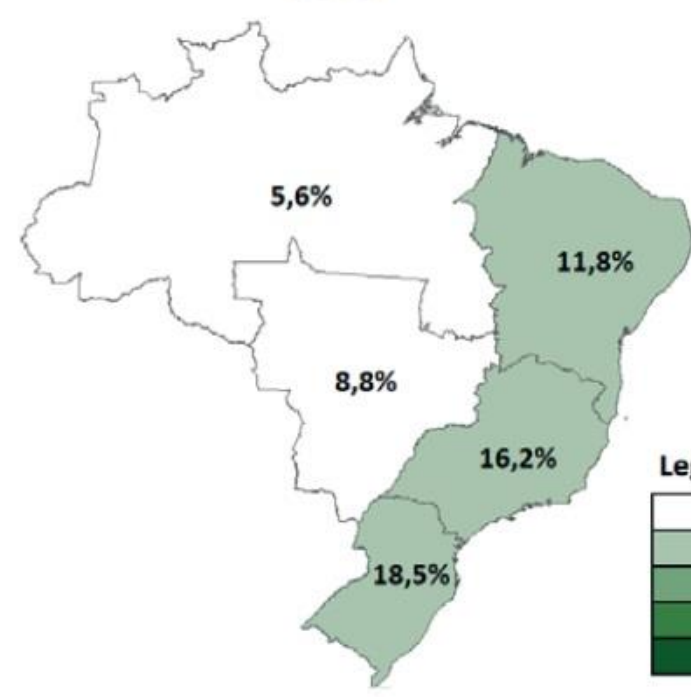

2013

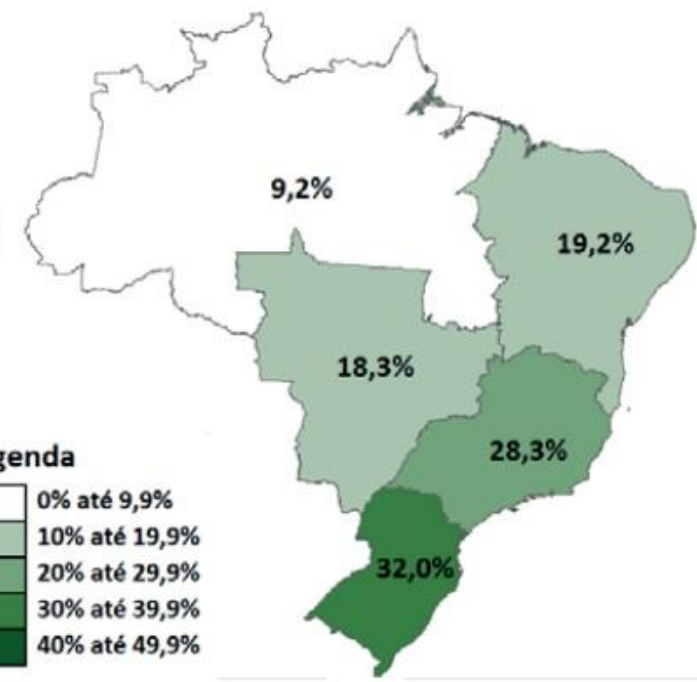

Fonte: BRASIL, 2015, p.29 
Já o gráfico 6, no mesmo sentido do que foi apresentado no gráfico 5, apresenta as diferenças percentuais de atendimento na faixa etária de 0-3 anos por regiões. Porém, como já destacamos anteriormente, os números no tocante ao atendimento à creche são pouco expressivos se comparados a pré-escola, também escondendo diferenças regionais ainda mais evidentes pelos baixos números.

A região Norte é detentora da menor taxa de frequência, que em 2013 atendia apenas 9,2\% da população de 0-3 anos, e teve o menor avanço percentual no período observado, apenas 3,6\%.

Diferentemente do segmento pré-escola, a região Sul em 2004 já representava a maior taxa de frequência à creche $(18,5 \%)$, mantendo-se na ponta do atendimento em 2013 com 32\% da população de 0-3 anos, expressando um aumento de 13,5\% no período de 2004 a 2013, e conjuntamente com a região Sudeste (28,3\%), tem as maiores taxas de frequência nesse segmento.

O gráfico 7 revela que houve uma diminuição na desigualdade em termos percentuais da população que frequentava préescola rural e urbana, entre 2004 e 2013. Em 2004 , havia uma diferença de $23,1 \%$ na relação entre a população rural e urbana, sendo que em 2013 essa diferença diminuiu consideravelmente para $10,4 \%$, o que ainda nos permite afirmar que existia uma considerável distância no que se refere ao atendimento de crianças com idade entre 4-5 anos, apresentando a população da região rural um menor atendimento em relação à urbana.

Gráfico 7. Percentual da população brasileira de 4-5 anos que frequentava escola por localização da residência.

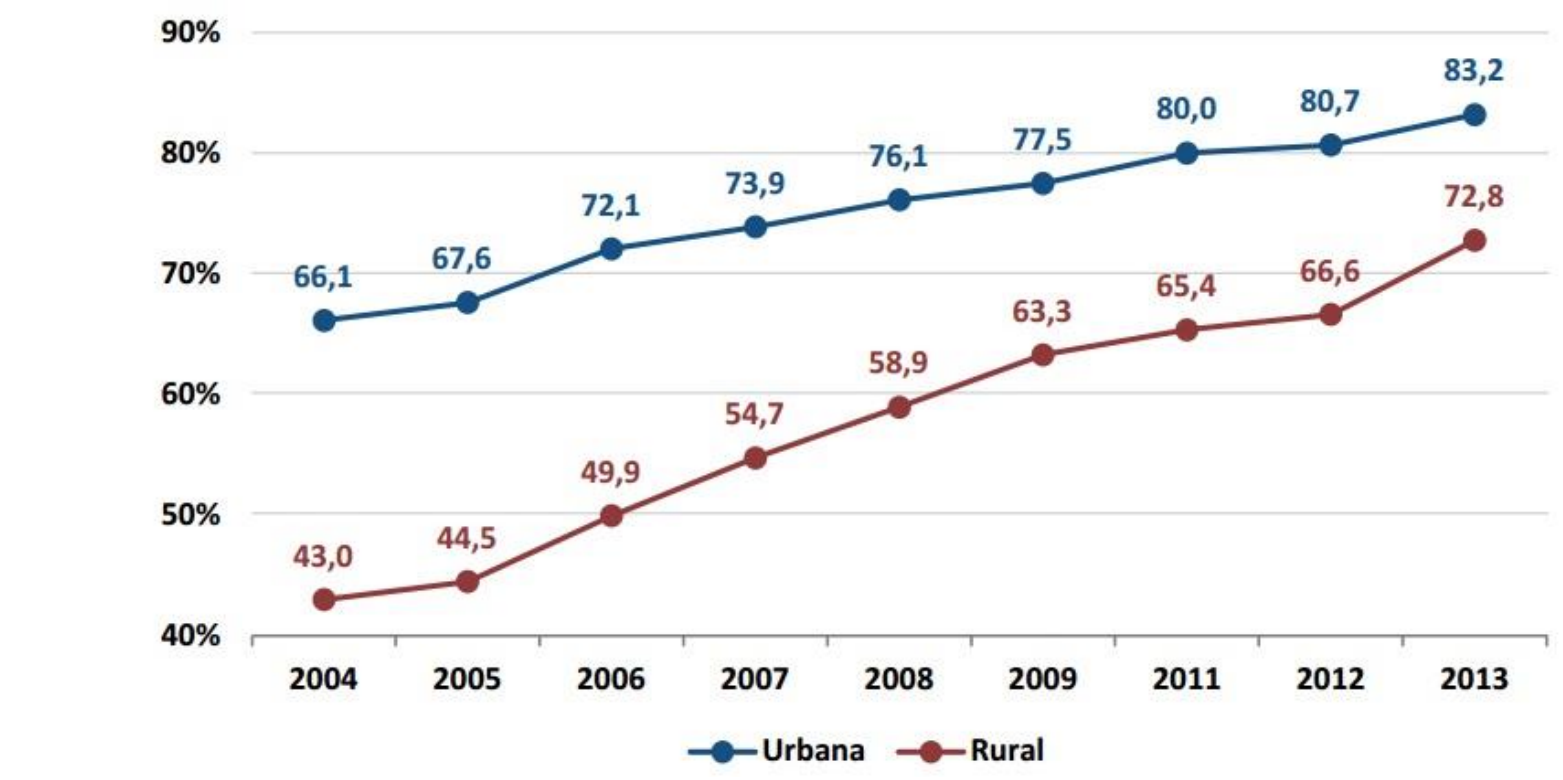

Fonte: Brasil (2015, p.27) 
Gráfico 8. Percentual da população brasileira de 0-3 anos que frequentava escola por localização da residência.

$50 \%$

$40 \%$

$30 \%$
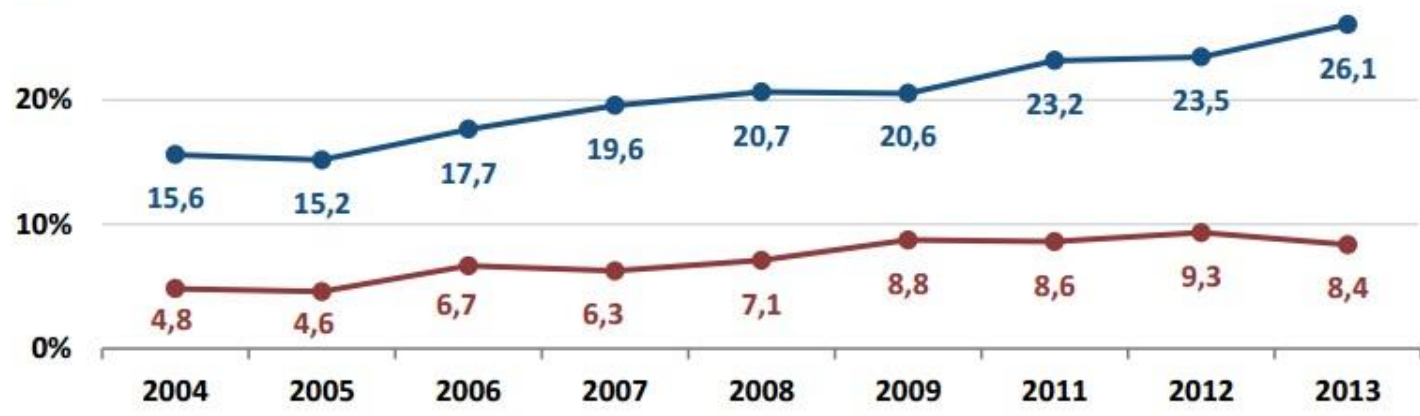

Fonte: Brasil (2015, p.31)

No que se refere à frequência das crianças com idade de 0-3 anos residentes nas áreas rural ou urbana, os números são muito pequenos, e o atendimento às crianças pequenas na área rural revela-se muito inferior do que as que residem em perímetro urbano. Essa diferença cresceu consideravelmente entre os anos 2004 e 2013. Em 2004, 15,5\% da população urbana frequentava creche, e apenas $4,8 \%$ população rural frequentava o mesmo nível de ensino, portanto, uma diferença de $10,8 \%$ que cresceu consideravelmente, chegando em 2013 a uma diferença de $17,7 \%$. Importante observar que as taxas de frequência nesse segmento têm oscilado um pouco em número de crescimento. Tal observação vem reforçar que o segmento não tem sido o foco das políticas públicas de educação.

Os gráficos 9 e 10 indicam que tanto para a população de 0-3 anos, quanto para a população de 4-5 anos, a frequência à escola apresenta certa desigualdade em termos étnicoraciais, e que no que se refere aos anos de 2004 até 2013 , a população negra tem frequência mais baixa do que a população branca, portanto, a escola infantil tem uma maior presença branca no período analisado.

Gráfico 9. Percentual da população brasileira que frequentava escola com 4-5 anos, por raça/cor

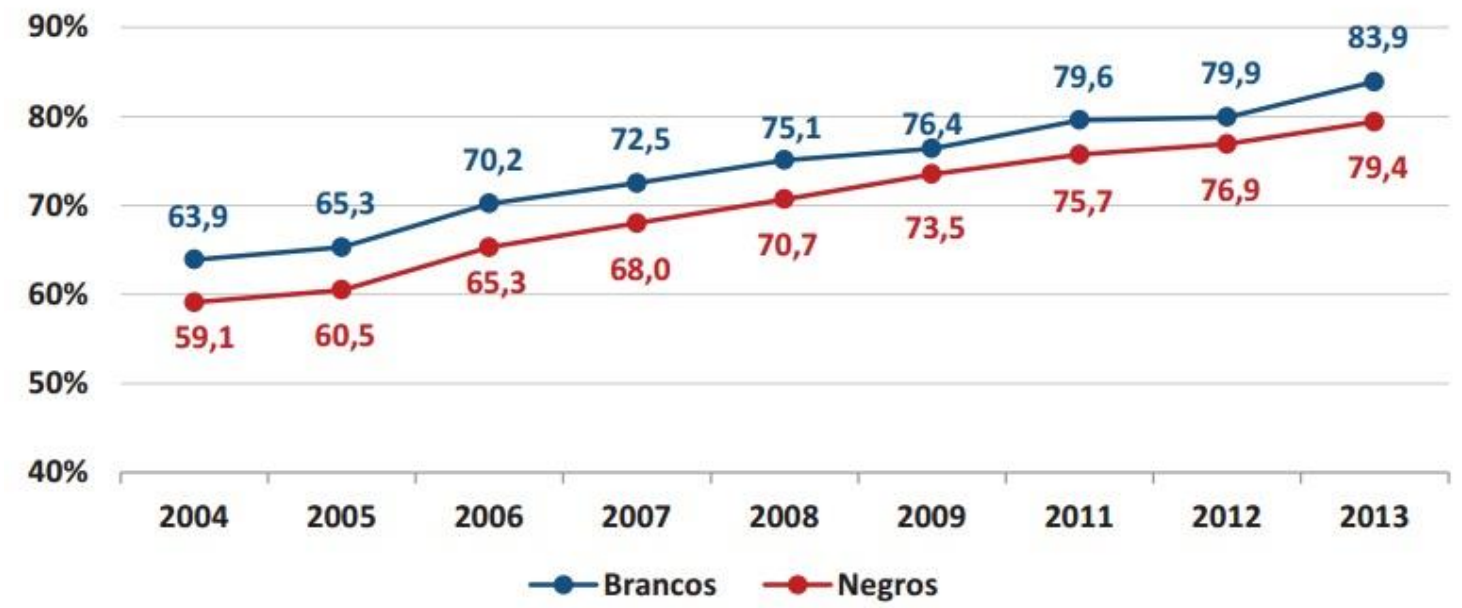

Fonte: Brasil (2015, p.27) 
Gráfico 10. Percentual da população brasileira que frequentava escola com 0-3 anos, por raça/cor

$50 \%$

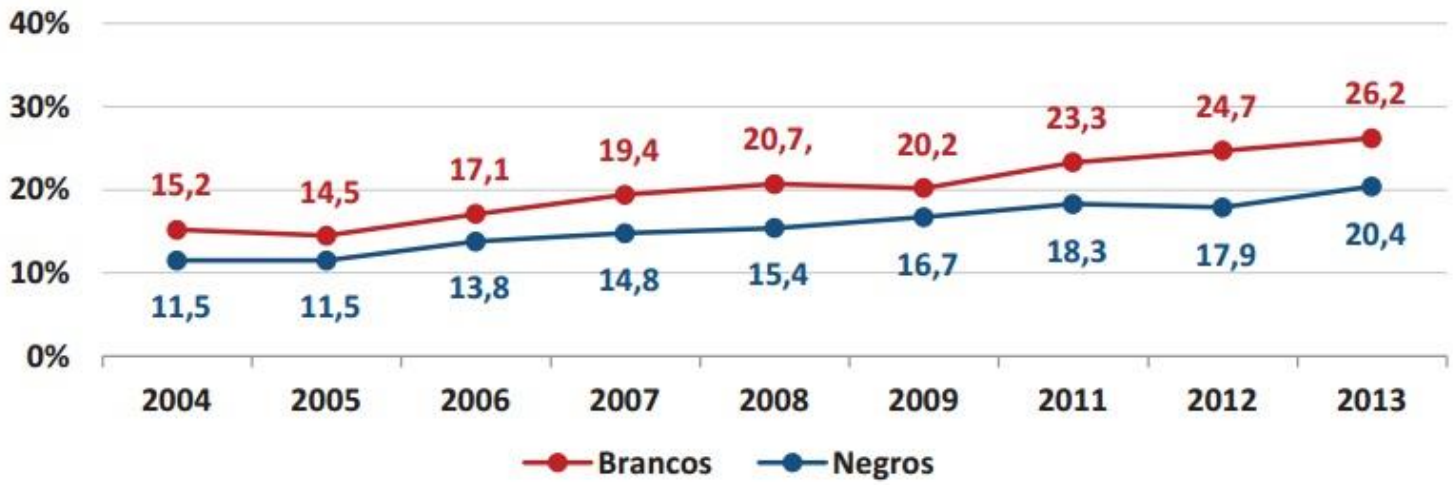

Fonte: Brasil (2015, p.32)

Com relação aos fatores econômicos, notamos grandes diferenças, pois o fator renda é variável importante quando pensamos a frequência na escola infantil. Desse modo, o gráfico 11 revela que desde 2008 mais de $90 \%$ da população mais rica, com idade entre 4 e a 5 anos, frequentava a pré-escola, enquanto 0 quartil mais pobre da população cresceu constantemente, e em 2013, chega a marca de $75,5 \%$ frequentando a escola, implicando num aumento significativo de investimento em escolas para a faixa de 4-5 anos, principalmente no setor público que atende as crianças mais pobres, diminuindo as desigualdades que em 2004 chegava a uma diferença de $30,4 \%$.

Gráfico 11. Percentual da população brasileira de 4-5 anos de idade que frequentava a escola, por quartis de renda domiciliar per capita

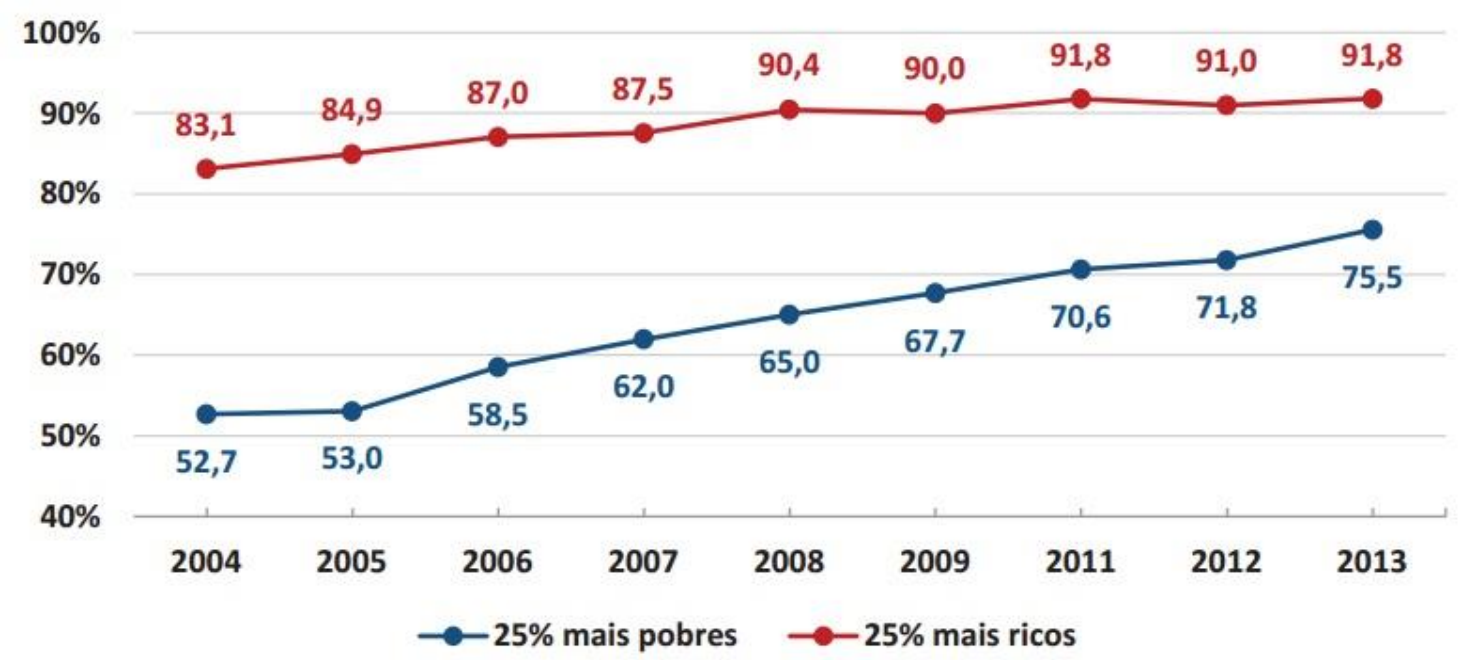

Fonte: Brasil (2015, p.28)

0 indicador renda per capita no segmento creche revela que, embora tanto a população do quartil de renda mais baixo quanto do mais alto tenham aumentado a frequência na escola infantil, o número de crianças do quartil mais rico é muito maior (gráfico 12). Nesse sentido, a frequência das crianças mais pobres avançou apenas $6,2 \%$ entre 2004 e 2013, porém, no que se refere aos mais ricos, o avanço no mesmo período se deu em $12,8 \%$, e a distância entre os mais pobres e os mais ricos alargou-se para $19,9 \%$. 
Gráfico 12. Percentual da população brasileira de 0-3 anos de idade que frequentava a escola, por quartis de renda domiciliar per capita

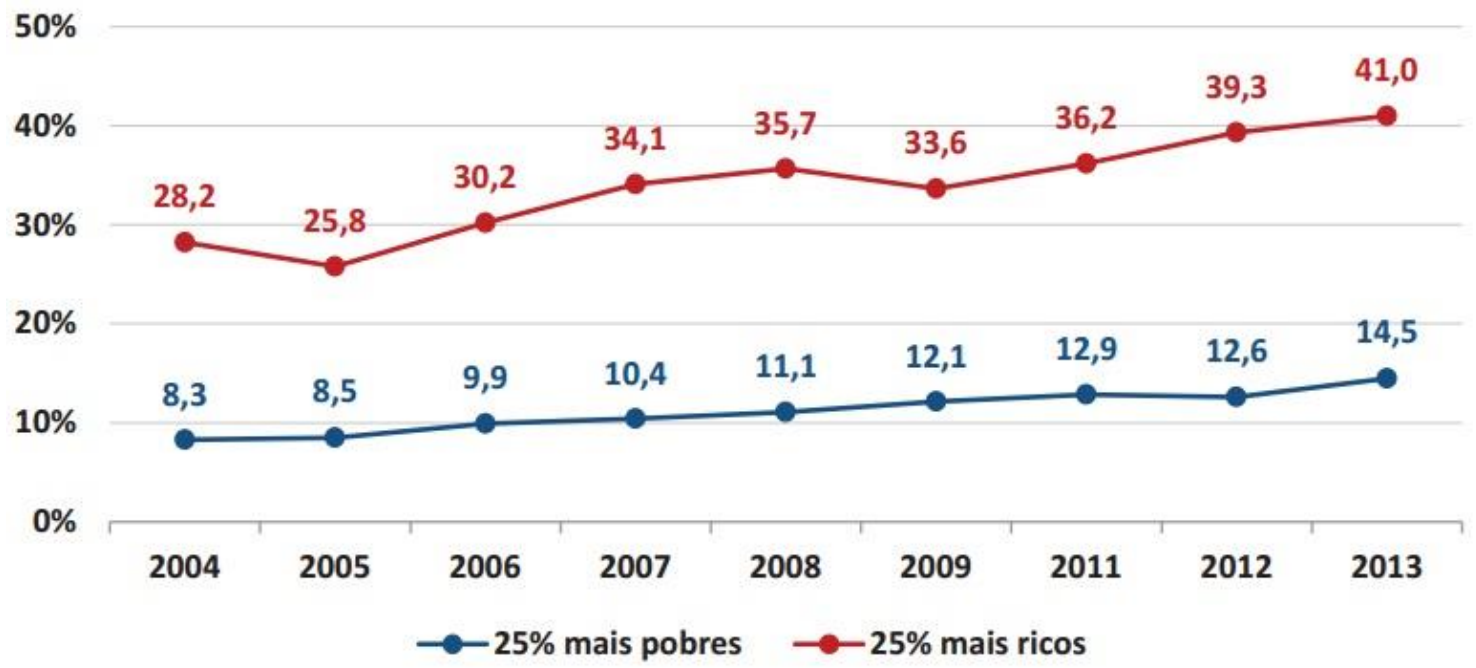

Fonte: Brasil (2015, p.33)

\section{DISCUSSÃO}

Com base nos dados apresentados, podemos concluir que o perfil predominante das crianças que frequentam a Educação Infantil brasileira pode ser definido como crianças brancas, residentes de região urbana e economicamente favorecidas, com maior frequência à pré-escola do que em creches.

A análise dos dados sobre as matrículas e a frequência na Educação Infantil no período investigado, revela que existe uma prevalência e prioridade política para o segmento pré-escola em detrimento da creche, revelando maior preocupação com o ensino que está mais próximo do Ensino Fundamental. Nesse sentido, a maior quantidade de matrículas está na préescola, que já se encontra praticamente universalizada, em escolas municipais e particulares, e a creche encontra-se muito longe da universalização, o que revela um aparente descaso com esse nível de ensino, embora instituído como um direito a todas as crianças brasileiras.

As diferenças crescem quando observadas as desigualdades regionais, e de renda principalmente, também sendo possível notar a maior presença de crianças de raça/cor branca em relação às negars, e uma maior frequência à Educação Infantil de crianças que residem nas cidades do que em área rural, e esse número aumenta quando observado por segmento (creche e pré-escola).

As preferências políticas pela pré-escola precisam ser superadas, principalmente pela afirmativa que a educação destinada à primeira infância é tão importante quanto à ofertada para crianças de 4 a 5 anos. Para tanto, também é necessário cumprir as políticas proclamadas para a creche, bem como aprimorar o financiamento desse nível educacional, avançando-se nas promessas para esse segmento.

Nesse sentido, precisamos de políticas que visem diminuir as desigualdades de acesso e permanência regionais, de raça/cor, de renda e da relação rural-urbano, como programas sociais que auxiliem o financiamento das famílias e permitam as condições materiais, bem como de transporte, vestuário e alimentação, para possibilitar o acesso àqueles que estão fora, e a permanência dos que já estão na escola infantil; o aumento da quantidade de vagas e a elevação da qualidade da educação infantil.

\section{REFERÊNCIAS}

BRASIL. Constituição (1988). Constituição da república Federativa do Brasil. Brasília, DF, Senado, 1988.

BRASIL. Lei no 9.394, de 20 de dezembro de 1996. Estabelece as diretrizes e bases da educação nacional. Diário Oficial da União, Brasília-DF, 23 dez. $\quad 1996 . \quad$ Disponível em: http://www.planalto.gov.br/ccivil 03/leis/19394. htm. Acesso em 12 fev. 2016.

BRASIL. Emenda constitucional no. 59, de 11 de novembro de 2009. Diário Oficial da União. Brasília, DF, 12 nov. 2009. Disponível em: 
http://www.planalto.gov.br/ccivil 03/constituica o/emendas/emc/emc59.htm. Acesso em: $15 \mathrm{fev}$. 2017.

BRASIL. Ministério da Educação. Câmara de Educação Básica. Resolução № 5, de 17 de dezembro de 2009. Diário Oficial da União. Brasília, 18 de dezembro de 2009, seção 1, p.18. Disponível em: http://www.seduc.ro.gov.br/portal/legislacao/RE SCNE005 2009.pdf. Acesso em: 10 jan. 2017.

BRASIL. Lei 13.005, de 25 de junho de 2014. Aprova o Plano Nacional de Educação - PNE e dá outras providencias. Diário Oficial da União. Brasília, DF, 26 jun. 2014. Disponível em: http://www.planalto.gov.br/ccivil 03/ ato20112014/2014/lei/l13005.htm. Acesso em: 10 jan. 2017.

BRASIL. Instituto Nacional de Estudos e Pesquisas Educacionais Anísio Teixeira. Plano Nacional de Educação PNE 2014-2024: Linha de Base. Brasília, DF: Inep, 2015.

CELLARD, A. A análise documental. In: POUPART, J. et al. A pesquisa qualitativa: enfoques epistemológicos e metodológicos. Petrópolis, Vozes, 2008. p. 295-316.

CRUZ, Priscila; MONTEIRO, Luciano. (Org). Anuário brasileiro da educação básica. SP: Moderna; Todos pela Educação, 2013.

KUHLMANN JR., Moysés. Histórias da educação infantil brasileira. Revista Brasileira de Educação, n.14, p. 5-18, mai./ago. 2000.

OLIVEIRA, M. M. Como fazer pesquisa qualitativa. Petrópolis, Vozes, 2007.

Recebido para publicação em: 04/11/2017

Revisado em: 30/01/2018

Aceito em: 10/03/2018 